\title{
Advanced and Effective Learning in Context Aware and Adaptive Mobile Learning Scenarios
}

\author{
doi:10.3991/ijim.v4i1.1129 \\ N. Uday Bhaskar and P. Govindarajulu \\ Sri Venkateswara University, Tirupati, India
}

\begin{abstract}
The ability to support students/learners to learn on the move at any place and at any time is new task to be addressed by using the mobile devices of the learners. Mobile technology support has given birth to the concept of mobile learning possessing a wide spectrum of applications and new teaching and learning techniques. This paper discusses a study conducted for undergraduate students on the effect of mobile technology usage in a learning process. The results showcased here indicate acceptance of the mobile devices into the learning process with a well appreciated enthusiasm from the learners.
\end{abstract}

Index Terms-Collaboration, Context, Mobile Learning, Learning Content.

\section{INTRODUCTION}

The rapid development of mobile technologies has catalytic behavior among students' and teachers' mobility, resulting in increased use of portable devices such as PDAs, Smartphones, mobile phones and tablet PCs with computationally enriched learning environment. The increased amount of research in mobile learning during the last few years like those that explores the potential of mobile and wireless devices to support learning, such as JAPELAS[1] or Ketamo's [2], is a motivating factor in this line of research.

A definition of learning context [3] is given as "any information that can be used to characterize the situation of learning entities that are considered relevant to the interactions between a learner and an application". There are many proposed taxonomies and definitions of context. Dey, Abowd and Salber [4] gave four categories: Identity, Location, Status and Time. Many prototype systems $[5,6$, $7,8,9]$ have utilized context to support learning. Much of this contextual information is gathered or generated and transmitted by tutors and by learners [3].

The suitability of learning activities change from one learner feature to another, and to their particular situation/scenario in an m-learning system. Also multi skills can be developed through individual or collaborative learning activities. In the system [10] by Martin et al, the users can accomplish activities either individually or collaboratively and each of them may be in different contexts.

Messaging is one among the straightforward application of the mobile device usage as educational supporting tool. Some researches found the impact of new forms of teaching and learning and thereby better results [11]. An experiment $[12,13]$ at Kingston concluded in student's preference is more towards SMS when compared to email or web-based announcements. An exploration of mobile learning has been done at Stanford Learning Lab [14] and they envisioned that a good approach would be to fill the gaps of time by short (around 30 seconds to 10 minutes) learning modules in order to use the highly fragmented attention of the learner while on the move. One of the commonly stated characteristics of mobile learning content is that it should be delivered in short 'nuggets' rather than large units of information, which can be supported by appropriate use of different media types.

Positive results from other m-learning projects have motivated us to carryout a research case in involving mobile technology usage by the learners in a learning process among our students, institutional and environmental setup. This work is a one more step to understand mobile devices' support for the improvement of learning among learners.

The paper is organized as follows. In Section II, we present the case study and we elicit the design aspects of the study. In Section III, we present observations of the study and finally, in Section IV, we conclude the paper.

\section{CASE STUDY}

This is an experimental case study to identify the mobile technology impact on a learner and on his/her knowledge by observing learning activity with his/her mobile device. We try to identify by how much the impact of the mobile technology usage would be on a learner and on his/her knowledge, and also examined whether this would improve the overall learning experience of the learner. The study consists of mobile phone usage by learners. During the study, the learner receives mobile learning content through SMS or MMS or internet transfer. The learning content is delivered to the learner as per content delivery schedule. The study began by introducing the concept of mobile usage in the learning process to the participants and also educating them the technical aspects of the activity they would carryout and the cards they have to fill during the study period. At the end of the study period, the data was collected and they were asked to fill in a general questionnaire and another one which is learner's learning activity dependent question form that helped in identifying the level of new information and knowledge he/she acquired during the study period.

The participants were 28 final year under graduate students who are also working towards their final project work in the department. The study period was around 30 days (4 weeks approx) including working days and holidays.

In figure 1, we present the overview of the m-learning scenario and the information/data flow of the study. The mobile learner is any participant of the study with his/her mobile device and may be in their own context which may 


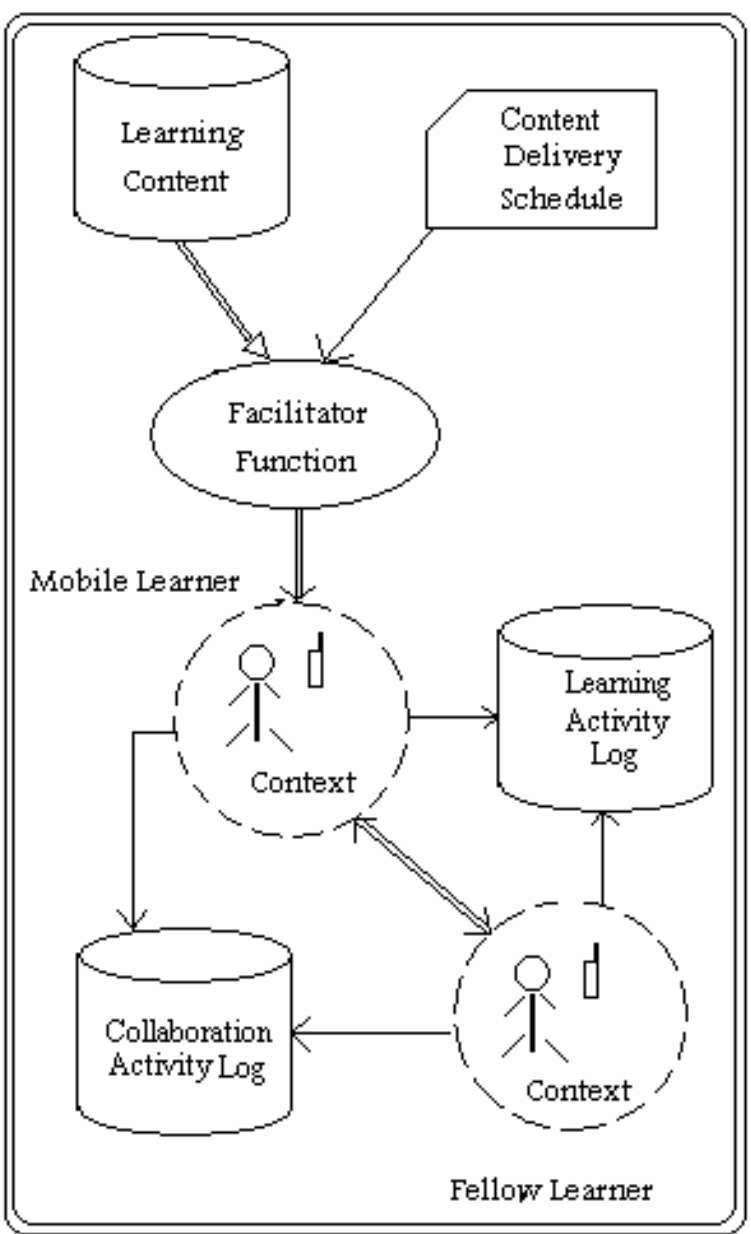

Figure 1. Overview of the M-Learning Scenario

be similar or different to other mobile learner's context. The facilitator function does carryout the task of inspecting the content delivery schedule and delivering the learning content to the learners. The other aspects are elicited in the subsections that follow the text.

\section{A. Mobile Learning Content}

The mobile learning content was prepared in 4 different course subject papers. The learning content was prepared by four faculty members of the department, and all of them were given prior information on how the learning content structure should be. The learning content is modeled in such a way that when it is read (text) or viewed (image/video) or heard (audio), the learner spends nearly 30 seconds to 5 minutes of time duration in the learning activity. Each learning content nugget/packed/capsule is assigned a content-code that was used in analysis of the collected usage data in the results. The text form of the learning content dominated all other forms in the study. As the learners (participants) are also carrying out their project works, the learning content was developed in such a manner that, when the leaner performs the learning activity over the delivered learning content, he/she would gain knowledge that could be useful to solve the problems associated with his/her project work.

\section{B. Learning Context}

As the mobile learner is not static/stationary, keeps on moving and performing different activities at different times in different places, the context plays role in the learning activity of the learner. The contexts that were considered in the study come under two sets. First, the set of all contextual elements with their values when the learning content is received by the learner. Second, the set of all contextual elements with their values when the learner performs learning activity with the delivered learning content. The set of these contextual elements are a) Time of the day b) Type of the Day c) Mode of the mobile device d) Physical Activity of the learner and e) Place of the learner at the time of learning activity. The intention behind considering two sets of context with their contextual elemental values is to identify individual learner's preference for performing learning activity in different contexts which may be other than the contextual elemental values when the learning content is actually delivered.

\section{Learning Activity Log}

The information about the learner's learning activity is collected in Learning Acitivity Log. Whenever the learner performs/carryout the learning activity with the delivered learning content using his/her mobile device, the Learning Acitivity Log gets populated with the data that is generated. Some aspects of the Learning Acitivity Log are the contextual elements like day, activity and place. The values/data for these contextual elements are collected from the learner by passive context awareness [15]. The dataset for the Learning Acitivity Log is identified for the learning content by using the content code designated for each learning content nugget/packet that is delivered to the learner.

The structure of the Learning Acitivity Log stores information such as Content Code, From Whom Content is received, Received Date, Time, Day, Mode of the Device, Physical Activity of the Learner, and Place of the learner, Action Performed by the learner over the received content with additional details of contextual information like Date, Time, Day, Mode, Physical Activity, Place, Percent Performed, and Time Spent in the learning activity.

The learning content to the learner comes from two sources. First, the facilitator responsible for sending the learning content to the learner as per delivery schedule. The other is any learner in need to collaborate in a learning activity. Few sample values were taken out of the collected data from the study are presented here for information. It has been observed from the collected data, that 'Physical Activity' has taken values like 'stationary', 'walking', 'traveling' and 'in a group'. For 'Place', the values were like 'class', 'lab', 'home', and 'public place'. It has been observed from the collected data that the Action Performed had sequence of interactions against the learning content by the learner.

\section{Collaboration Activity Log}

As the learners are also carrying out the project works team wise, they share knowledge among themselves to solve issues that pop up in the solution process. The learning content delivered to the learners is not same for all the learners and in particular not to the learners of same team. The learner collaborates with the project member to solve the problems/issues they face as part of the project work. The collaboration data populates the Collaboration Activity Log whenever he/she collaborates with the other learner through his/her mobile device. 
The structure of the Collaboration Activity Log stores information such as Content Code, Sender of the learning content nugget, Receiver of the learning content nugget, along with contextual information such as Date on which the content is received, Time of receiving of the content, Day on which the content is received, Place in which the learner is at the time of receiving the learning content, and Physical Activity of the learner. The Collaboration Activity Log gets populated whenever a learner collaborates with other learner through mobile device. The values of the contextual elements are collected by passive context awareness [15].

\section{E. Delivery Schedule}

The delivery schedule deals with the learning content delivery to the learners based on the specific design attributes taken into consideration. First, the timings of the day has been slotted into 8 different slots as i) Tutor Hours ii) Break Hours iii) Lunch Hours iv) Early Hours v) Morning Hours vi) Evening Hours vii) Night Hours and viii) Late Hours. Second, the designation of timings and the selected hours has been designed by taking into consideration the different contexts that the learners would be, in these slots. Third, the schedule is designed and executed in a group wise fashion. Each of the 7 groups are considered groupby-group when the learning content is delivered, for over 30 days and covering 8 slots of every day. It is also designed taking into account that the learners are carrying out their project work as teams, and to identify their collaboration in solving the problems related to the project work with the new knowledge they gain from the delivered learning content to their mobile devices.

\section{OBSERVATIONS}

Once the study period was completed, the data has been collected from the learners / participants. On observation it is found that one student failed to show any interest during the study period and hence we have considered the data of the remaining 27 learners for further analysis. The following text presents the usage statistics, result analysis and learners' interests \& reactions collected as part of the study.

\section{A. Mobile Learner Preferences}

The tables 1 and 2 show the identified preferences of the learners in different contexts. The results have shown wider and variety preferences of the learners in reference to physical activity versus learning content and place of the learner versus learning content.

As advised, the learners did not switch off the mobile devices during the study period. Most of the learners preferred video form of learning content when their place context is home/hostel. A few learners have preferred more than one form of the learning content for the same context. One point that comes out here is, we can not and need not worry about in what common contexts the learners would be in; which would be against the very essence of adaptation to the learner's context and support him in his/her learning activities. What we stress here is there are always many combinations that come up in the results of studies like these, the idea is to show that we need to adapt to the individual learner's context and maximize the results of any learning activity he/she carries out in that context.

\section{B. Mobile Learning Activity}

The learning activity during the study period was just increasing as weeks are passing by. The values in the table 3 show the learning activity of all the participants during the period of 4 weeks. Third week has produced more learning activity and on observation we found that week having 3 holidays in it. The learners have spent most of their leisure time with their device for learning purpose. So, we can also assert that, mobile learning through mobile devices will be close to the learners at all times and they don't feel of whether they are in the class or lab, they just keep working with it at leisure and acquire more and more knowledge with their learning activities.

We have conducted a short examination after the study period of 30 days is completed. we observe that the results were very much good and encouraging (Figure 2). Among the participating 27 learners, 20 of them acquired more than their average percentage when compared to their regular academic percentage. 2 of them had shown no difference and 5 of them has got less percent of success than their academic percent. On the whole, the study has shown $74 \%$ positive results on using mobile devices in the learning process.

TABLE I.

PHYSICAL ACTIVITY VS LEARNING CONTENT

\begin{tabular}{|c|c|c|c|c|}
\hline $\begin{array}{c}\text { Physical } \\
\text { Activity Con- } \\
\text { text }\end{array}$ & \multicolumn{4}{|c|}{ Learning Content Type } \\
\cline { 2 - 5 } & Text & Video & Audio & Image \\
\hline Walking & 11 & 0 & 16 & 0 \\
\hline Stationary & 3 & 14 & 3 & 7 \\
\hline In a Group & 4 & 3 & 0 & 20 \\
\hline Travelling & 4 & 7 & 14 & 3 \\
\hline
\end{tabular}

TABLE II.

Place Vs Learning CONTENT

\begin{tabular}{|c|c|c|c|c|}
\hline \multirow{2}{*}{$\begin{array}{c}\text { Location } \\
\text { Context }\end{array}$} & \multicolumn{4}{|c|}{ Learning Content Type } \\
\cline { 2 - 5 } & Text & Video & Audio & Image \\
\hline Class Room & 7 & 14 & 0 & 7 \\
\hline LAB & 7 & 4 & 4 & 14 \\
\hline Library & 18 & 0 & 0 & 14 \\
\hline $\begin{array}{c}\text { Hostel/ } \\
\text { Home }\end{array}$ & 4 & 21 & 4 & 11 \\
\hline Campus & 18 & 4 & 7 & 7 \\
\hline $\begin{array}{c}\text { Public } \\
\text { Places }\end{array}$ & 14 & 4 & 7 & 0 \\
\hline
\end{tabular}

TABLE III.

LEARNING ACTIVITY DURING THE STUDY PERIOD

\begin{tabular}{|c|c|}
\hline Week Number & Learning Activity Size \\
\hline 1 & 108 \\
\hline 2 & 165 \\
\hline 3 & 290 \\
\hline 4 & 324 \\
\hline
\end{tabular}




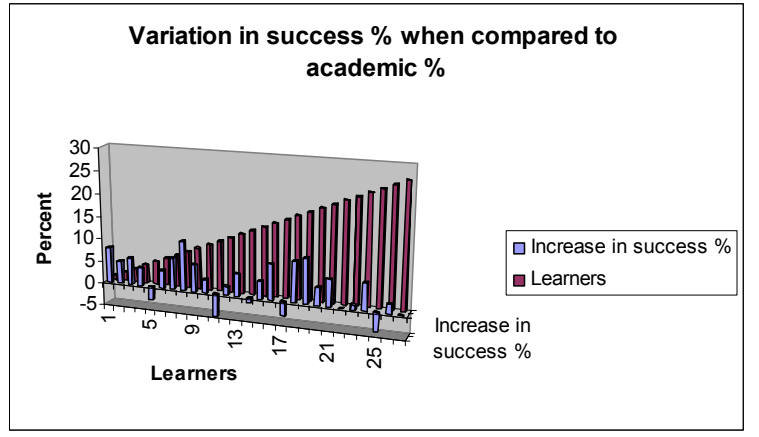

Figure 2. Success percent compared to academic percent

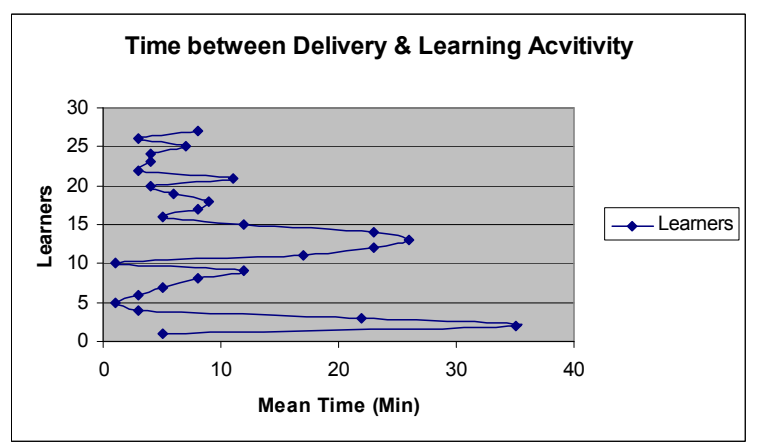

Figure 3. Response Time

As far as the response time towards the delivered learning content is considered, it was quick and immediate. The graph in figure 3 depicts the mean values of the time gap (response time) between the learner's learning activity time and the learning content received time, for all the learners. $63 \%$ of the learners carried out the learning activity within the first 10 minutes (mean) after they receive the learning content. Only very few did carry out learning activity with more time gap, which may be due to many reasons in which the learners and their context in which they are present.

Regarding Collaboration among the learners, the results were good and informative. The collaboration happened between the team members who are carrying out final year project work as one group. Much of the collaboration happened within the group members and cross group collaboration was very less. Members of team three (table 4) have shown very less collaboration when compared to other teams. On enquiry, they complained against the high cost of SMS/MMS services their mobile service provider is charging. Teams seven and one too have shown less collaboration. It has been observed that the cost for different services is a factor in carrying out collaborated learning activity through the mobile devices.

\section{Mobile Learner Interests}

The learners' interests and reactions are collected from the general questionnaire and targeted interaction with the learners. Table 5 shows the mean time ( in minutes) the learners are willing to devote in learning activity over different forms/types of the learning content that is delivered to their mobile devices. As expected, the learners are willing to spend 1 to 2 minutes for text type and 8 to $18 \mathrm{~min}$ utes for video type of learning content. When asked the learners about their unwillingness to spend more time (e.g., hours), the common reaction was "its mobile device, we can't spend so much time with it continuously".
TABLE IV.

COLLABORATION

\begin{tabular}{|c|c|}
\hline $\begin{array}{c}\text { Project Team } \\
\text { Number }\end{array}$ & $\begin{array}{c}\text { Collaborated Learning } \\
\text { Activity Size }\end{array}$ \\
\hline 1 & 22 \\
\hline 2 & 35 \\
\hline 3 & 12 \\
\hline 4 & 65 \\
\hline 5 & 78 \\
\hline 6 & 29 \\
\hline 7 & 19 \\
\hline 8 & 45 \\
\hline
\end{tabular}

TABLE V.

CONTENT TYPE VS DURATION

\begin{tabular}{|c|c|}
\hline Learning Content & Mean Time(Min) \\
\hline Text & 1.2 \\
\hline Audio & 6.1 \\
\hline Video & 9.7 \\
\hline Image/ Diagram & 2.4 \\
\hline
\end{tabular}

TABLE VI.

TIME Vs CONTENT TYPE

\begin{tabular}{|c|c|c|c|c|}
\hline \multirow{2}{*}{ Session } & \multicolumn{4}{|c|}{ Learning Content Type } \\
\cline { 2 - 5 } & Text & Audio & Video & Image \\
\hline $\begin{array}{c}\text { Early Hours } \\
\text { Slot }\end{array}$ & 7 & 7 & 0 & 11 \\
\hline $\begin{array}{c}\text { Morning } \\
\text { Hours Slot }\end{array}$ & 11 & 16 & 0 & 0 \\
\hline $\begin{array}{c}\text { Forenoon } \\
\text { Hours Slot }\end{array}$ & 7 & 0 & 13 & 7 \\
\hline $\begin{array}{c}\text { Afternoon } \\
\text { Hours Slot }\end{array}$ & 5 & 0 & 11 & 11 \\
\hline $\begin{array}{c}\text { Evening } \\
\text { Hours Slot }\end{array}$ & 1 & 11 & 14 & 1 \\
\hline $\begin{array}{c}\text { Late Evening } \\
\text { Hours Slot }\end{array}$ & 8 & 8 & 8 & 3 \\
\hline $\begin{array}{c}\text { Nights Hours } \\
\text { Slot }\end{array}$ & 10 & 10 & 7 & 0 \\
\hline $\begin{array}{c}\text { Late Nights } \\
\text { Hours Slot }\end{array}$ & 6 & 3 & 0 & 3 \\
\hline
\end{tabular}

The values of the table 6 give us the information regarding the preference of the learners over learning content type and different timings of a given day. The values indicate wider interests of the learners between content type and timings. Against to our expectations, good number of learners spend their time to carry out learning activity in the early morning hours, and also more number of them interested in diagrammatic information. It has been observed that, learners are not interested in spending time to carry out learning activity during the late night hours. Except in the evening hours, the learners have exhibited interest in all other forms/types of learning content over different timings of the day almost evenly. There was less preference to audio type in the forenoon and afternoon hours. 
Nearly $75 \%$ of the learners reported that the learning content was easy in all cases and $25 \%$ indicated difficulty in few cases. Only $12 \%$ of the learners felt boring in some cases regarding the learning content they receive. To our surprise, $75 \%$ of the learners have shown interest in permanently storing the received learning content in their mobile devices even after performing the learning activity successfully. $38 \%$ of the learners want to set their own timings and places to perform learning activity with their mobile device and don't want to get interrupted without their permission. The learners have indicated acceptance to carryout learning activity through mobile devices at any time and any place. We observed the acceptance of the learners for any contextual values of time and place is $63 \%$, and have shown positive sign.

\section{CONCLUSION}

As said in the beginning it is the very nature of the mobility that props up interest in the learning activity among the learners with their mobile devices and helps in nurturing a habit of learning any time and any where is again proved in out case study. The primary aspect of our study shows that the learner is interested in this new form of learning through his/her mobile device and which also resulted in the increase in acquiring his/her knowledge to new levels. The results of our study helps us to conclude that such studies with wider variety of contexts and large number of learners with a long duration of study period would reveal more and more useful and vital information regarding the mobile learners intentions and attitude towards this new learning paradigm.

\section{REFERENCES}

[1] H. Ogata, Y. Yano, "Context-aware support for computersupported ubiquitous learning", Proceedings of IEEE International Workshop on Wireless and Mobile Technologies in Education, IEEE Computer Society, Taiwan, 2004, pp. 27-34.

[2] H. Ketamo, "mLearning for kindergarten's mathematics teaching", Proceedings of WMTE 2002, Sweden,2002.

[3] Yuan-Kai Wang (2004), "Context Awareness and Adaptation in Mobile Learning", In the Proceedings of the second IEEE International Workshop on Wireless and Mobile Technologies in Education (WMTE'04).

[4] A.K. Dey, G.D. Abowd, D. Salber, " A conceptual framework and a toolkit for supporting the rapid prototyping of context-aware applications", Human Computer Interaction, 16, PP.97-166,2001.

[5] G.D. Abowd, G.G. Atkeson, A. Feinstein, et. Al, "Teaching and learning as multimedia authoring: the classroom 2000 project", Proceedings of MM'96, pp.187-198, ACM Press,1996.
[6] A.F. Bobick, S.S. Intille, J.W.Davis, F. Baird, C. S. Pinhanez, L.W. Campbell, Y.A.Ivanov, A. Schutte, A Wilson, " The KidsRoom : a perceptually-based interactive and immersive story environment", M.I.T Media laboratory Perceptual Computing Section technical Report No.398, November, 1996, Revised june 1998.

[7] A. Iles, D. Glaser, M. Kam, J. Canny, "Learning via Distributed dialogue: Livenotes and handheld Wireless Technology", In Proc. Of conf. on computer support for Collaborative Learning, Colorado, January 2002.

[8] K. Ryokai, C. Vaucelle, J. Cassell, "Literacy Learning by Storytelling with a Virtual Peer", Proceedings of Computer Support for Collaborative learning, January 7-11, Boulder, CO, PP. 352-360, 2002.

[9] I. R. Nourbakhsh, "Robots and Education in the classroom and in the museum: On the study of robots, and robots for study", IEEE Int. Conf. Robotic Automation, 2000.

[10] Estefania Martin, Nuria Andueza, Rosa M. Carro (2006), "Architecture of a System for Context-based Adaptation in M-Learning", In the Proceedings of the Sixth International Conference on Adavanced Learning Technologies (ICALT'06).

[11] Dvorak J. K., Burchanan K., "Using Technology to Create and Enhance Collaborative Learning", Proc. Of $14^{\text {th }}$ World Conference on Educational Multimedia, Hypermedia and Telecommunications 2002, Denver, CO, USA, June 2002.

[12] Stone A., Briggs J, "ITZ GD 2 TXT - How to Use SMS Effectively in M-Learning", proceedings of the European Workshop on Mobile and Contextual Learning, (p 11-14), Birmingham, UK, June 2002.

[13] Stone A, Briggs J, Smith C, "SMS and Interactivity - Some Results from the Field, and its Implications on Effective Uses of Mobile Technologies in Education". Proc. Of IEEE International Workshop on Wireless and Mobile Technologies in Education, Vaxjo, Sweden, August 2002.

[14] "Mobile Learning Explorations at the Stanford Learning Lab", A newsletter for Stanford academic community, speaking of computers, Issue 55, January 8, 2001.

[15] Louise Barkhuus and Anind Dey, "Is Context-Aware Computing Taking Control away from the User? Three Levels of Interactivity Examined", UbiComp 2003, LNCS 2864, pp. 149-156, 2003

\section{AUTHORS}

Uday Bhaskar Nagella is a Research Scholar in the department of Computer Science, Sri Venkateswara University, Tirupati, India. He can be reached by udaynagella@gmail.com.

Dr. P. Govindarajulu, Professor, department of computer science, Sri Venkateswara University, Tirupati, India. He can be reached by pgovindarajulu@yahoo.com.

Submitted 08 October 2009. Published as resubmitted by the authors on December, 2, 2009. 